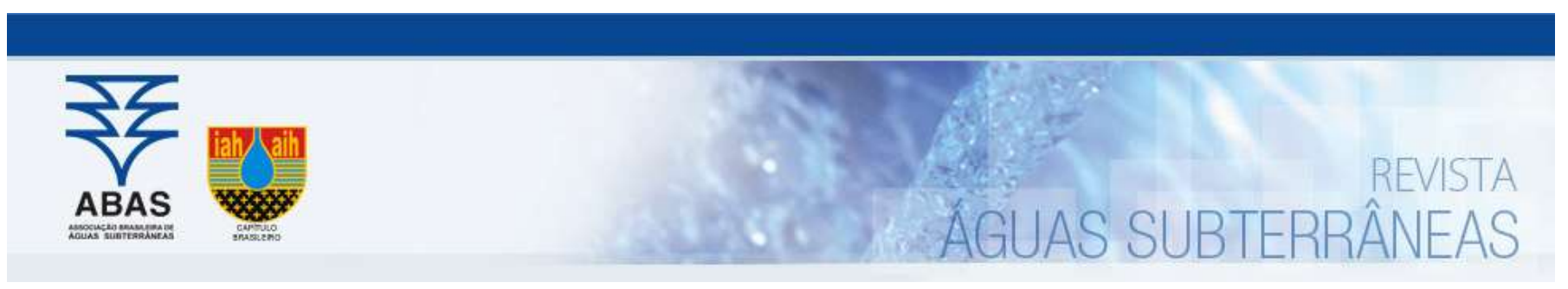

Estudos de Caso e Notas Técnicas

\title{
Análise exploratória de dados da qualidade da água de poços amazonas na cidade de Macapá, Amapá, Brasil
}

\section{Exploratory analysis of water quality data from Amazon wells in Macapá city, Amapá, Brazil}

\author{
Luciane Picanço da Silva $^{1}$; Jardel Pinto Barbosa ${ }^{1}$; Gabriel Araujo da Silva ${ }^{\circledR}$ \\ 1 Universidade do Estado do Amapá (UEAP), Macapá, AP \\ $\triangle$ luhcianessilva@gmail.com, jardelpquantum@gmail.com, prof.gabriel.araujo@gmail.com
}

\begin{abstract}
Resumo
Esta pesquisa teve como objetivo analisar parâmetros físico-químicos e microbiológicos das águas de poços amazonas localizadas no bairro Novo Horizonte da cidade de Macapá/AP, que são utilizados para consumo da população local, almejando o despertar do conhecimento sobre a qualidade da água e cuidados inerentes ao poço, através da aplicação de cartilha educacional. Os períodos para coleta foram definidos em estiagem (novembro 2016) e chuvas (março 2017), com as amostras de água coletadas em frascos estéreis de polietileno com lacre de 1 litro em 20 poços amazonas. Os procedimentos analíticos foram realizados in loco e no Laboratório de Química Orgânica e Bioquímica da Universidade do Estado do Amapá (UEAP). Os parâmetros analisados foram: $\mathrm{pH}$, turbidez, alcalinidade, acidez, dureza total, cloretos, sólidos totais, coliformes totais e termotolerantes. Todas as análises foram realizadas em duplicata. De acordo com os resultados, tendo por base a Portaria do Ministério da Saúde $N^{\circ} 2914$, de 12 de dezembro de 2011 que dispõe sobre os procedimentos de controle e de vigilância da qualidade da água para consumo humano e seu padrão de potabilidade, concluiu-se que o bairro Novo Horizonte apresentou um índice negativo na qualidade da água subterrânea utilizada pela população local com a presença de coliformes e, após análise exploratória dos dados por HCA, PCA e boxsplot, observou-se as variações conexas de pH, alcalinidade, dureza e cloretos, sobretudo, no período chuvoso.
\end{abstract}

Palavras-chave:

Qualidade da água.

Água subterrânea.

Análise exploratória.

Abstract

The aim of this work was to analyze the physicochemical and microbiological parameters of amazon wells located in the Novo Horizonte, Macapá, AP, which are used for consumption by the local population, aiming to awaken knowledge about water quality and care Inherent to the well, through the application of an educational primer. The sample were collected in drought (November 2016) and rains (March 2017), with water samples stored in 1 liter sterile polyethylene bottles with sealing in 20 amazon wells. The analytical procedures were carried out in loco and in the Laboratory of Organic Chemistry and Biochemistry of the State University of Amapá (UEAP). The analyzed parameters were: pH, turbidity, alkalinity, acidity, total hardness, chlorides, total solids, total and thermotolerant coliforms. All analyzes were performed in duplicate. According to the results, based on the Ordinance of the Ministry of Health No. 2914, of December 12, 2011, which establishes procedures for the control and monitoring of water quality for human consumption and its drinking water standard, it was concluded that the Novo Horizonte neighborhood had a negative index on the groundwater quality used by the local population with the presence of coliforms and, after exploratory analysis of the data by HCA, PCA and boxsplot, the related variations of pH, alkalinity, hardness and chlorides, especially in the rainy season.

DOI: http://dx.doi.org/10.14295/ras.v32i1.28941

\section{INTRODUÇÃO}

A água é um importante recurso natural e o principal fator de sobrevivência da humanidade e de toda a natureza viva. Ter o acesso à água é um direito de todo cidadão, no entanto, pela falta ou péssimas condições de distribuição da água pelas gestões públicas, a população do bairro Novo Horizonte da cidade de Macapá - AP provê o seu abastecimento por meio de fontes disponíveis chamadas de águas subterrâneas, captadas através de poços perfurados em seu local de residência (ANA, 2010; BACCI et al., 2008; REBOUÇAS, 2001).

Segundo a Associação Brasileira de Águas Subterrâneas (ABAS, 2016), água subterrânea é toda água que circula abaixo da superfície da terra e que pode ser encontrada devido aos poros e fissuras das rochas sedimentares e compactas que permitem a movimentação da água. Durante a circulação nos quais a água percola entre os poros do subsolo e das rochas permeáveis flu- 
indo para reservatórios subterrâneos, a água passa por um artifício de depuração e processos físico-químicos e bacteriológicos que alteram as suas qualidades tornando-se, particularmente, mais apropriada ao consumo humano.

O poço, um recurso de acesso à água cada vez mais crescente no Brasil e no mundo, vem a ser um grande vazio interligando um amplo número de poros ou fissura de rochas. Popularmente, pelas regiões do Brasil, pode ser identificado como amazonas, cacimba, poço raso ou cisterna. Estes são escavados manualmente e, de ordem, captam sempre a água dos aquíferos não confinados, ou seja, o primeiro lençol freático, chegando a profundidades de 20 metros. Ainda, pode ser identificado como poço artesiano captando água dos aquíferos confinados, chegando a profundidades de 40 metros e perfurado por máquinas, onde as águas fluem do solo sem a necessidade de bombeamento devida à própria pressão hidrostática (ABAS, 2016; Dicionário Livre de Geociências, 2016; GROTT, 2016; VASCONCELOS, 2017).

De certa forma pode-se aplicar aos mananciais subterrâneos uma característica de potabilidade devido serem filtrados e purificados naturalmente. São propriedades que tornam o seu uso mais vantajoso para o consumo em residências e indústrias, pois possui um baixo custo de captação em comparação com o abastecimento e tratamento de águas superficiais (REBOUÇAS, 2004).

Contudo, os mananciais não estão livres dos impactos negativos da atividade antrópica, biológica ou natural entre rocha e água que afetam diretamente a qualidade da água. A falta destes conhecimentos induz os moradores do bairro Novo Horizonte a não avaliarem a necessidade da utilização racional das águas subterrâneas, a preservação dos mananciais e, principalmente, a realização de análises prévias da qualidade da água usufruída (REBOUÇAS, 2006).

Desse modo, esta pesquisa teve o objetivo de analisar determinados parâmetros físico-químicos e microbiológicos das águas de poços amazonas, com aproveitamento de cartilha educacional e aplicação de uma análise exploratória dos dados, de forma a servir para uma melhor compreensão e conscientização da sociedade local, inserida em um contexto de uso dos poços como alternativa para muitos moradores que padecem a falta de abastecimento de água (OLIVEIRA et al., 2009; VILLAR, 2016).

\section{MATERIAL E MÉTODOS}

O estudo foi realizado no bairro Novo Horizonte, localizado na zona norte da cidade de Macapá, estado do Amapá (Figura 1), apresentando uma população estimada em 24.360 habitantes segundo bairro mais populoso - com 5.782 domicílios distribuídos em uma área total de $15,3 \mathrm{~km}^{2}$ - o maior bairro da cidade em extensão - possuindo um quantitativo de 4.943 poços (IBGE 2010).

Figura 1 - Localização da área de estudo

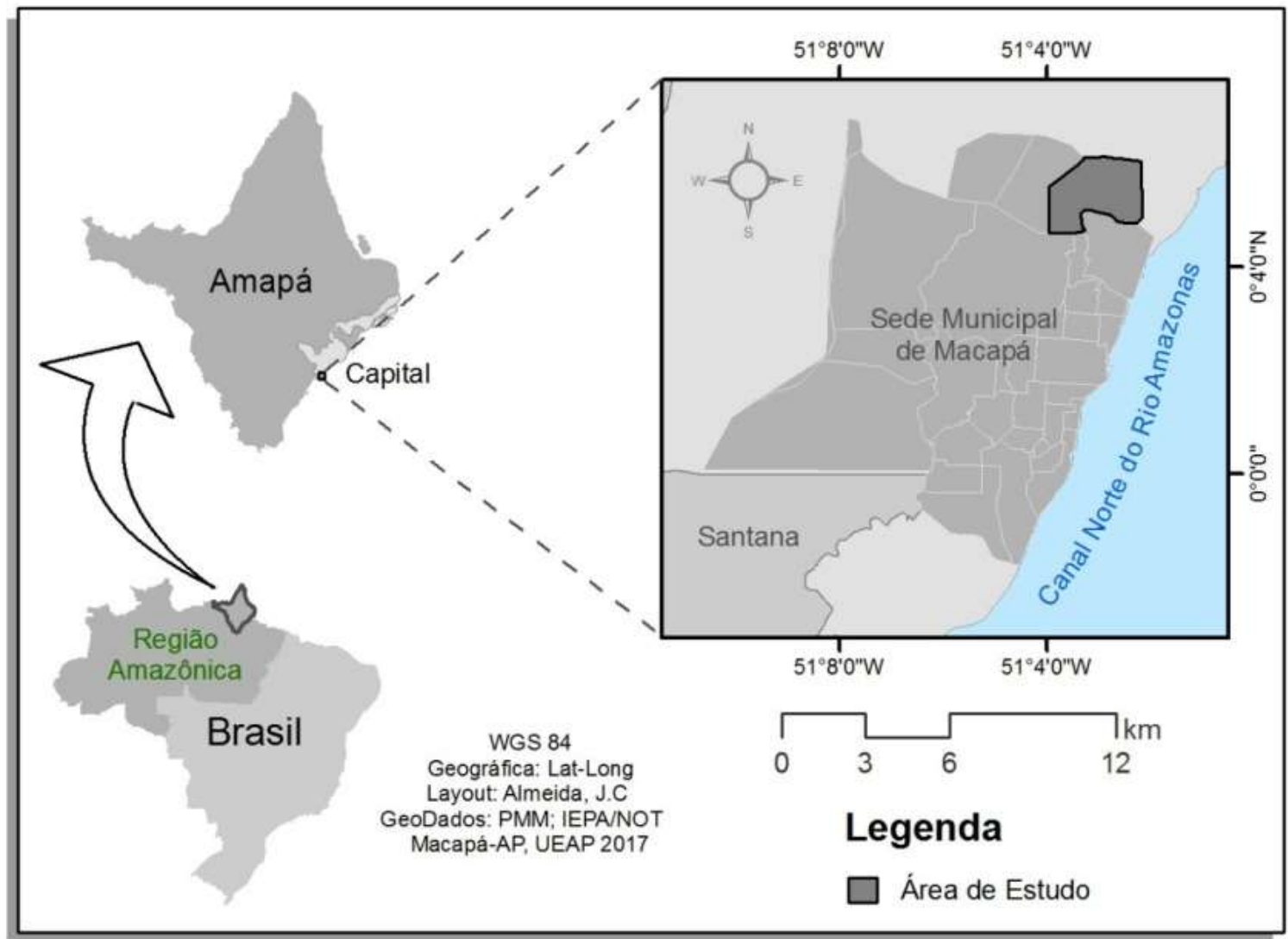

Fonte: Autora (2017) 
O período do estudo foi iniciado em abril de 2016 se estendendo até abril de 2017 , com coleta no período de estiagem (novembro 2016) e chuvas (março 2017). A amostragem espacial da pesquisa foi determinada aleatoriamente em 20 pontos de coleta em poços amazonas, enquadradas em quatro zonas de coleta demarcadas em: zona A, B, C e D e, em cada zona efetuada a coleta em três pontos, totalizando 40 amostras no decorrer dos dois períodos, como é demonstrada na figura 2.

Figura 2 - Mapa do Bairro Novo Horizonte

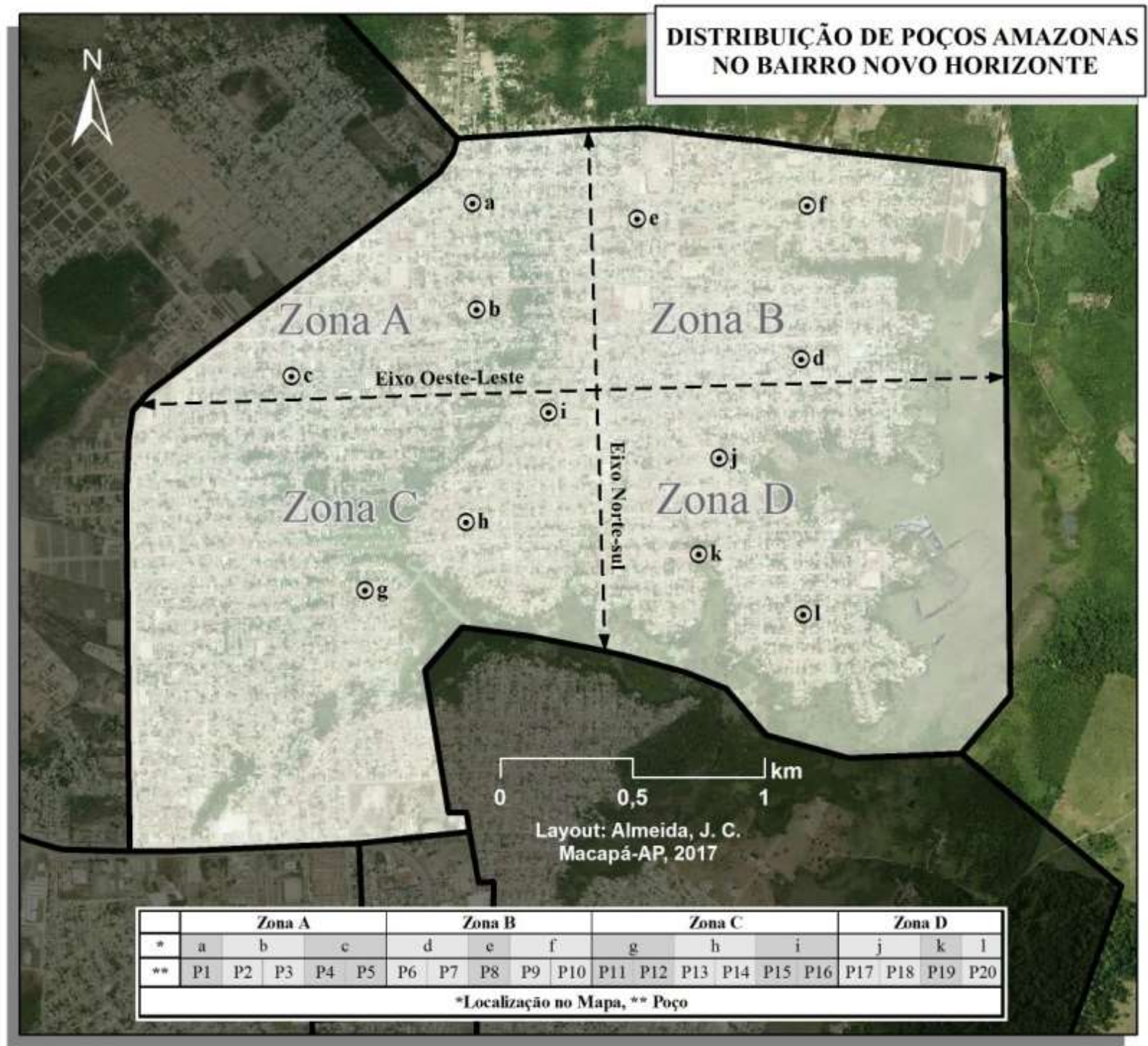

Fonte: Autora (2017)

Legenda: Divisão em quatro (4) zonas: A, B, C e D; demarcadas pelas linhas pontilhas - Rua Cícero Marquês de Souza (vertical) e Rua Joaquim Silva do Amaral (horizontal) - indicando os locais de coleta das águas dos poços amazonas

Os procedimentos analíticos foram realizados in loco e no Laboratório de Química Orgânica e Bioquímica da Universidade do Estado do Amapá. As amostras foram coletadas em frascos estéreis de polietileno com lacre de 1 litro, devidamente identificadas e preservadas refrigeradas até o momento de análise, sendo considerados sete (07) parâmetros: $\mathrm{pH}$, pelo método potenciométrico, com auxílio de um pHmêtro; turbidez, pelo turbidímetro Policontrol AP2000®; alcalinidade, acidez, cloretos e dureza total pelo método titulométrico; sólidos totais, pelo método gravimétrico. Os métodos utilizados foram segundo Parsons (2013), Saggar et al. (2015) e protocolos oficiais da Fundação Nacional de Saúde (FUNASA, 2014) e da American Public Health Association (APHA).

Para o parâmetro microbiológico referenciou-se as bactérias do grupo coliformes que são indicadoras de contaminação e, em geral, originam-se no intestino de animais de sangue quente. Especificamente analisaram-se os grupos de coliformes totais (CT) e termortolerantes - Escherichia coli (EC) -, utilizando-se o método do substrato cromogênico Colilert ${ }^{\circledR}$, adicionado em um erlenmeyer estéril contendo uma alíquota de $100 \mathrm{ml}$ de amostra e em seguida levado a solução para ser incubada a $37^{\circ} \mathrm{C}$ em estufa por 24 horas (BUCKALEW et al, 2006).

As leituras feitas com auxílio de uma lâmpada ultravioleta expressaram o resultado com determinação qualitativa: positivo ou negativo. Leu-se positivo para coliformes totais as amostras com presença de coloração amarela e, para coliformes termotolerantes a apresentação de solução amarela e fluorescência na presença de luz UV-325 nm. Apontou-se teste negativo com apresentação incolor das soluções (BUCKALEW et al, 2006). 
Para maior detalhamento aplicou-se um questionário com perguntas sobre a identidade do poço e seus arredores, a fim de observar o nível de conhecimento dos usuários sobre a preservação do poço, a qualidade da água utilizada e os cuidados necessários para sua ingestão e foi gerada uma cartilha educacional com as informações obtidas. A avaliação das análises das águas foi realizada com auxílio da Portaria $N^{\circ} 2.914$, de 12 de dezembro de 2011 do Ministério da Saúde (MS) que dispõe sobre os parâmetros e seus valores máximos permitidos (VMP) que caracterizam o enquadramento dos corpos de água dentro do padrão ambiental previsto em lei.

A partir dos parâmetros alcalinidade, cloretos, dureza, sólidos totais e turbidez das águas retirados dos poços amazonas, realizou-se uma análise descritiva dos dados através das médias e desvios padrões em ambos os períodos, utilizando o software Excel ${ }^{\circledR}$ (2007). Utilizou-se o gráfico do boxplot para estudo das variabilidades do $\mathrm{pH}$ nas amostras a partir do programa $\mathrm{R}$ Core Team (2017).

Através de software estatístico de análise multivariada, utilizouse o processamento autoescale com duas componentes principais para os poços amazonas (scores), utilizando os descritores de alcalinidade, cloretos, dureza, sólidos totais e turbidez das respectivas águas nos períodos de chuva e estiagem. A análise multivariada faz uso de métodos estatísticos em amostras com uma grande quantidade de dados (multivariados), utilizam técnicas exploratórias de sintetização da estrutura de variabilidade dos dados. (MINGOTI, 2005).

A Análise de Componentes Principais (PCA, Principal Component Analysiss), tem como objetivo principal explicar a estrutura de variância e covariância de um vetor aleatório de um conjunto de $n$ variáveis aleatórias, através de combinações lineares. Estas combinações lineares são denominadas componentes principais e são não correlacionadas. (MINGOTI, 2005).

Análise Hierárquica de Agrupamentos (HCA) divide os elementos da amostra ou população, em grupos "cluster" de forma que os elementos de um mesmo grupo (scores) sejam similares entre si com relação às variáveis (descritores) e os elementos em grupos diferentes sejam heterogêneos em relação a estas mesmas características (MINGOTI, 2005).

Os agrupamentos são feitos a partir de medidas de similaridade e dissimilaridade (distâncias entre as amostras). Existem diversos métodos de agrupamento hierárquicos, dentre os principais estão o de ligação completa (complete linkage), média das distâncias (average linkage), de ligação simples (single linkage), e etc.

O método de ligação completa (complete linkage) foi aplicado aos parâmetros de alcalinidade, cloretos, dureza, sólidos totais e turbidez das águas de poços, com intuito de verificar a existência de possíveis padrões ou similaridades nas regiões de localização dos poços amazonas na área de estudo na cidade de Macapá, nos períodos de chuva e estiagem, e nessa etapa foi utilizado o software estatístico MiniTab® 18 (2010).

\section{RESULTADOS E DISCUSSÕES}

De acordo com os resultados, observou-se que a maioria dos parâmetros analisados está em desconformidade com a Portaria $\mathrm{N}^{\circ}$ 2.914, de 12 de dezembro de 2011 do MS, com variações significativas no período de estiagem (Tabela 1) e chuvas (Tabela 2).

Para os valores de $\mathrm{pH}$ que representam a intensidade das condições ácidas ou alcalinas do meio líquido por meio da presença de íons hidrogênio $\left(\mathrm{H}^{+}\right)$, observou-se uma distinção entre os períodos, os resultados variaram de 5,85 a 6,02 durante a estiagem (Tabela 1) e 3,72 a 5,63 durante as chuvas (Tabela 2), não se enquadrando aos padrões da portaria do MS entre 6,0 e 9,5 para o consumo humano.

Possivelmente, as alterações de $\mathrm{pH}$ ocorreram devido a atividade de organismos no consumo do oxigênio durante as reações com a matéria orgânica gerando um alto teor de gás carbono dissolvido, assim como também pela dissolução de rochas e o contato com despejos domésticos (SILVA et al., 2017).

Tabela 1 - Resultados dos parâmetros físico-químicos no período de estiagem (novembro, 2016)

\begin{tabular}{|c|c|c|c|c|c|}
\hline Parâmetro & $\begin{array}{c}\text { Zona A } \\
\text { Estiagem }\end{array}$ & $\begin{array}{c}\text { Zona B } \\
\text { Estiagem }\end{array}$ & $\begin{array}{c}\text { Zona C } \\
\text { Estiagem }\end{array}$ & $\begin{array}{c}\text { Zona D } \\
\text { Estiagem }\end{array}$ & VMP \\
\hline Físico-Químicos & $X \pm D P$ & $\mathrm{X} \pm \mathrm{DP}$ & $X \pm D P$ & $X \pm D P$ & \\
\hline $\mathrm{pH}$ & $6,02 \pm 0,04$ & $5,90 \pm 0,18$ & $5,88 \pm 0,18$ & $5,85 \pm 0,57$ & $6,0-9,0^{(1)}$ \\
\hline $\begin{array}{l}\text { Turbidez } \\
\text { (NTU) }\end{array}$ & $0,05 \pm 0,07$ & $3,28 \pm 4,12$ & $10,71 \pm 25,18$ & $11,85 \pm 21,67$ & $5^{(1)}$ \\
\hline $\begin{array}{l}\text { Alcalinidade } \\
\left(\mathrm{mg} \text { de } \mathrm{CaCO}_{3} / \mathrm{L}\right)\end{array}$ & $3,89 \pm 0,87$ & $3,57 \pm 1,00$ & $5,51 \pm 2,22$ & $3,81 \pm 1,78$ & ND \\
\hline $\begin{array}{l}\text { Acidez } \\
\left(\mathrm{mg} \text { de } \mathrm{CO}_{2} / \mathrm{L}\right)\end{array}$ & 0,00 & 0,00 & 0,00 & 0,00 & ND \\
\hline $\begin{array}{l}\text { Cloretos } \\
\text { (mg de } \mathrm{Cl} / \mathrm{L} \text { ) }\end{array}$ & $23,14 \pm 11,34$ & $12,00 \pm 1,73$ & $22,18 \pm 9,67$ & $16,13 \pm 11,12$ & $250^{(1)}$ \\
\hline $\begin{array}{l}\text { Dureza Total } \\
\left(\mathrm{mg} \text { de } \mathrm{CaCO}_{2} / \mathrm{L}\right.\end{array}$ & $17,80 \pm 15,40$ & $9,10 \pm 4,09$ & $4,75 \pm 3,31$ & $12,75 \pm 5,96$ & $500^{(1)}$ \\
\hline Sólidos Totais & $0,03 \pm 0,05$ & $0,03 \pm 0,05$ & $0,12 \pm 0,08$ & $0,04 \pm 0,03$ & $1000^{(1)}$ \\
\hline
\end{tabular}

(g L-)

Fonte: Autora (2017)

Nota: (1)Portaria N² 2.914 de 12 de dezembro de 2011 - Ministério da Saúde; VMP = Valores Máximos Permitidos; ND = Não descrito da legislação; X = Média; DP = Desvio padrão 
Tabela 2 - Resultados dos parâmetros físico-químicos no período de chuva (abril, 2017)

\begin{tabular}{|c|c|c|c|c|c|}
\hline Parâmetro & $\begin{array}{l}\text { Zona A } \\
\text { Chuva }\end{array}$ & $\begin{array}{l}\text { Zona B } \\
\text { Chuva }\end{array}$ & $\begin{array}{l}\text { Zona C } \\
\text { Chuva }\end{array}$ & $\begin{array}{l}\text { Zona D } \\
\text { Chuva }\end{array}$ & VMP \\
\hline Físico-Químicos & $X \pm D P$ & $\mathrm{X} \pm \mathrm{DP}$ & $\mathrm{X} \pm \mathrm{DP}$ & $\mathrm{X} \pm \mathrm{DP}$ & \\
\hline $\mathrm{pH}$ & $4,14 \pm 0,53$ & $4,18 \pm 0,44$ & $5,63 \pm 0,42$ & $3,72 \pm 0,74$ & $6,0-9,0^{(1)}$ \\
\hline $\begin{array}{l}\text { Turbidez } \\
\text { (NTU) }\end{array}$ & $2,00 \pm 1,34$ & $4,92 \pm 3,64$ & $2,65 \pm 4,55$ & $15,16 \pm 21,63$ & $5^{(1)}$ \\
\hline $\begin{array}{l}\text { Alcalinidade } \\
\left(\mathrm{mg} \text { de } \mathrm{CaCO}_{3} / \mathrm{L}\right)\end{array}$ & $3,89 \pm 0,87$ & $3,57 \pm 1,00$ & $5,51 \pm 2,22$ & $3,81 \pm 1,78$ & ND \\
\hline $\begin{array}{l}\text { Acidez } \\
\left(\mathrm{mg} \text { de } \mathrm{CO}_{2} / \mathrm{L}\right)\end{array}$ & 0,00 & 0,00 & 0,00 & 0,00 & ND \\
\hline $\begin{array}{l}\text { Cloretos } \\
\text { (mg de } \mathrm{Cl} / \mathrm{L} \text { ) }\end{array}$ & $24,63 \pm 15,68$ & $15,11 \pm 6,89$ & $31,01 \pm 18,47$ & $17,09 \pm 7,53$ & $24,63 \pm 15,68$ \\
\hline $\begin{array}{l}\text { Dureza Total } \\
\left(\mathrm{mg} \text { de } \mathrm{CaCO}_{2} / \mathrm{L}\right)\end{array}$ & $17,80 \pm 15,40$ & $9,10 \pm 4,09$ & $4,75 \pm 3,31$ & $12,75 \pm 5,96$ & $17,80 \pm 15,40$ \\
\hline $\begin{array}{l}\text { Sólidos Totais } \\
\left(\mathrm{g} \mathrm{L} \mathrm{L}^{-}\right)\end{array}$ & $0,08 \pm 0,06$ & $0,09 \pm 0,03$ & $0,12 \pm 0,06$ & $0,12 \pm 0,05$ & $1000^{(1)}$ \\
\hline
\end{tabular}

\section{Fonte: Autora (2017)}

Nota: (1)Portaria N² 2.914 de 12 de dezembro de 2011 - Ministério da Saúde; VMP = Valores Máximos Permitidos; ND = Não descrito da legislação; X = Média; DP = Desvio padrão

Segundo NERY et al (2012), há a ocorrência de índices de baixo $\mathrm{pH}$ nas águas subterrâneas do bairro Zerão da cidade de Macapá/AP devido as condições sanitárias e a precária proteção dos poços, corroborando os resultados encontrados nesta pes- quisa que também apontam valores de $\mathrm{pH}$ abaixo da faixa recomendada pela portaria do MS, indicando a relativa acidez das águas. Para otimização da análise dos resultados obtidos para $\mathrm{pH}$, foi confeccionado um gráfico de boxsplot (Figura 3).

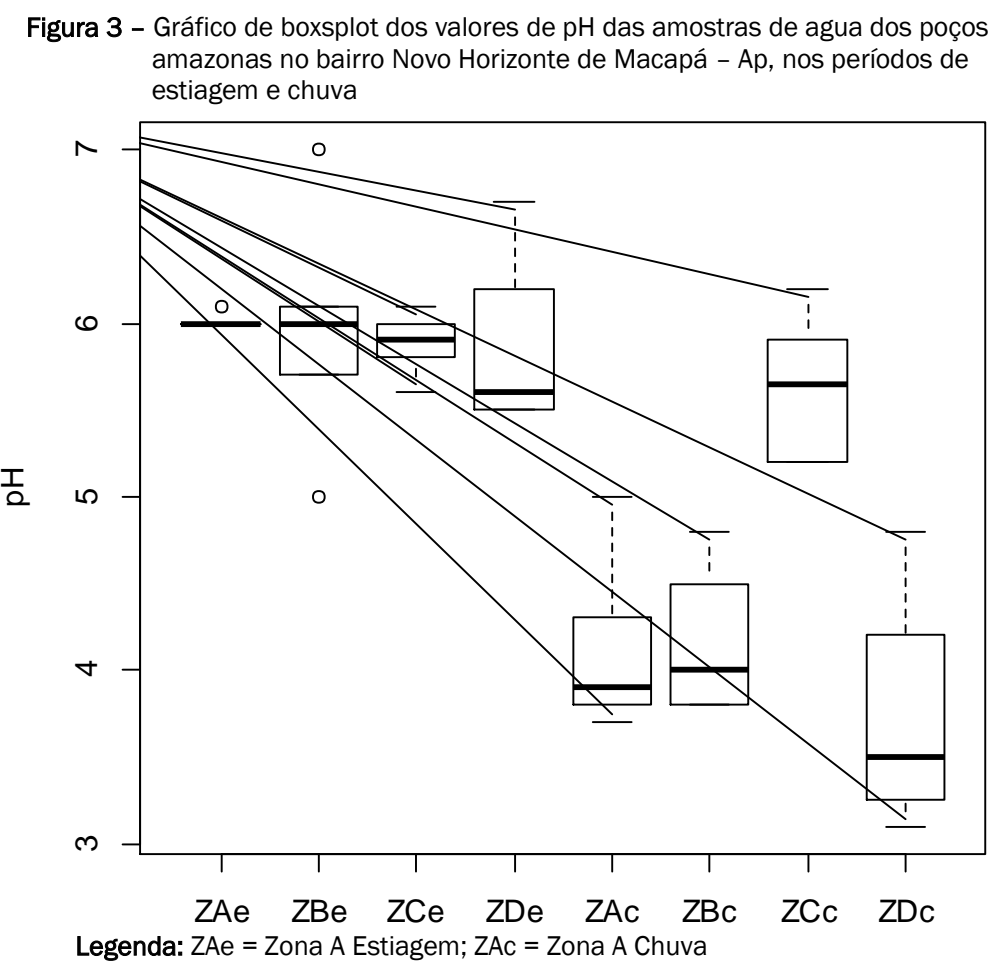

A notável queda de $\mathrm{pH}$ no período de chuva pode ser interpretada pela característica dinâmica dos lençóis freáticos que se localizam em baixas profundidades e possuem influência direta da alta precipitação pluviométrica que propicia a percolação dos contaminantes devido aos terrenos arenosos. É possível deduzir que devido ao clima tropical da região norte, a degradação da matéria orgânica é mais intensa na fase anaeróbica, favorecendo a produção de ácidos orgânicos e, por conseguinte pHs mais ácidos (SILVA et al, 2009).
A alcalinidade das águas decorre principalmente da presença de íns hidróxido $(\mathrm{OH}-)$, carbonato $\left(\mathrm{CO}_{3}^{2-}\right)$ e bicarbonato $\left(\mathrm{HCO}_{3}^{-}\right)$, possuindo a capacidade de neutralizar ácidos ou minimizar as variações significativas do $\mathrm{pH}$. A Portaria do MS não faz referências a esse parâmetro estabelecendo os limites de alcalinidade em água. Em função do $\mathrm{pH}$ das amostras há maior propensão a concentrações de bicarbonato nas águas, justificando-se pela presença do gás carbônico e sais dissolvidos em maior quantidade (BRASIL, 2006). 
Em relação à acidez, esta proporciona a habilidade da água em resistir às alterações de $\mathrm{pH}$ ocasionadas pelas bases. A origem da acidez pode ser natural ou antrópica, decorrendo basicamente da presença de carbonatos de origem biológica, como também mineral e orgânica a partir de indústrias. A Portaria do MS não faz referências a esse parâmetro estabelecendo os limites de acidez em água. Demonstrada pelas tabelas 1 e 2, as amostras de água revelaram uma acidez zero para todos os poços estudados, confirmando o fato de não haver indústrias nas proximidades do bairro (BRASIL, 2014).

Os cloretos podem estar presentes naturalmente em águas superficiais e subterrâneas, pois a água é um admirável solvente e pode agregar muitas substâncias dissolvidas. A Portaria do MS estabelece o teor de cloretos em $250 \mathrm{mg} \mathrm{L}^{-1}$ como VMP para água potável. Conforme os resultados, as águas dos poços amazonas das Zonas A, C e D possuem uma alta concentração de cloretos, especialmente, no período de chuvas (Tabela 2), possivelmente, ocorre da interação da água ao longo do seu percurso com o solo, predominantemente, arenoso do estado do Amapá (BRASIL, 2011).

O parâmetro de dureza total da água indica a concentração de íons de cálcio e magnésio em solução ou formação de precipitados. A dureza pode ocorrer da dissolução de rochas calcáreas, ricas em cálcio e magnésio ou a partir da presença de efluentes domésticos. De maneira satisfatória, as águas de todos os poços, tanto no período de estiagem quanto de chuvas, apresentaramse dentro do limite permitido conforme apresentado na Tabela 1 e 2 (BRASIL, 2014).

A turbidez da água é atribuída às partículas sólidas em suspensão que diminuem a sua transparência e pode ocorrer a partir de processos erosivos, presença de detritos orgânicos ou de forma antrópica pelo contato com os esgotos domésticos. A turbidez reduz a eficiência da cloração devido ao "efeito escudo" atribuído aos microrganismos patogênicos, impedindo a ação da desinfecção. Por representar um parâmetro estético, as amostras analisadas nesta pesquisa revelaram pequenas variâncias no período de estiagem (Tabela 1), atribuindo-se ao baixo nível de água presente nos poços (BRASIL, 2014).

Os sólidos totais presentes na água não devem exceder $1000 \mathrm{mg}$ $\mathrm{L}^{-1}$, segundo a portaria MS. A entrada de sólidos na água pode causar alterações de gosto se estiver acima do aceitável. Os resultados demonstrados na tabela 1 e 2 apontam que todas as amostras encontraram-se dentro do limite permitido para consumo humano durante os dois períodos (BRASIL, 2011).

Ainda, segundo OLIVEIRA et al (2004), a falta de conhecimento mínimo sobre saneamento e proteção das águas subterrâneas tende a sujeitar o sistema aquífero livre a fontes pontuais de contaminação, incluindo os próprios poços amazonas quando abandonados e, muitas vezes, servindo de saída de esgotos domésticos. Mediante a literatura revisada para o estado do Amapá, não foram encontrados níveis determinados sobre Cloretos, sendo evidenciado nesta pesquisa um alto nível presente nas águas, potencializando-se como um ponto de alerta para contaminação do solo, possivelmente, por ação antrópica.

Em elação ao parâmetro microbiológico, analisado com referência às bactérias coliformes totais e termotolerantes - Escherichia coli -, os resultados são demonstrados na tabela 3, indicando que mais de $50 \%$ dos poços possui presença de coliformes, seja em período de estiagem ou chuvas.

Tabela 3 - Resultados do parâmetro microbiológico

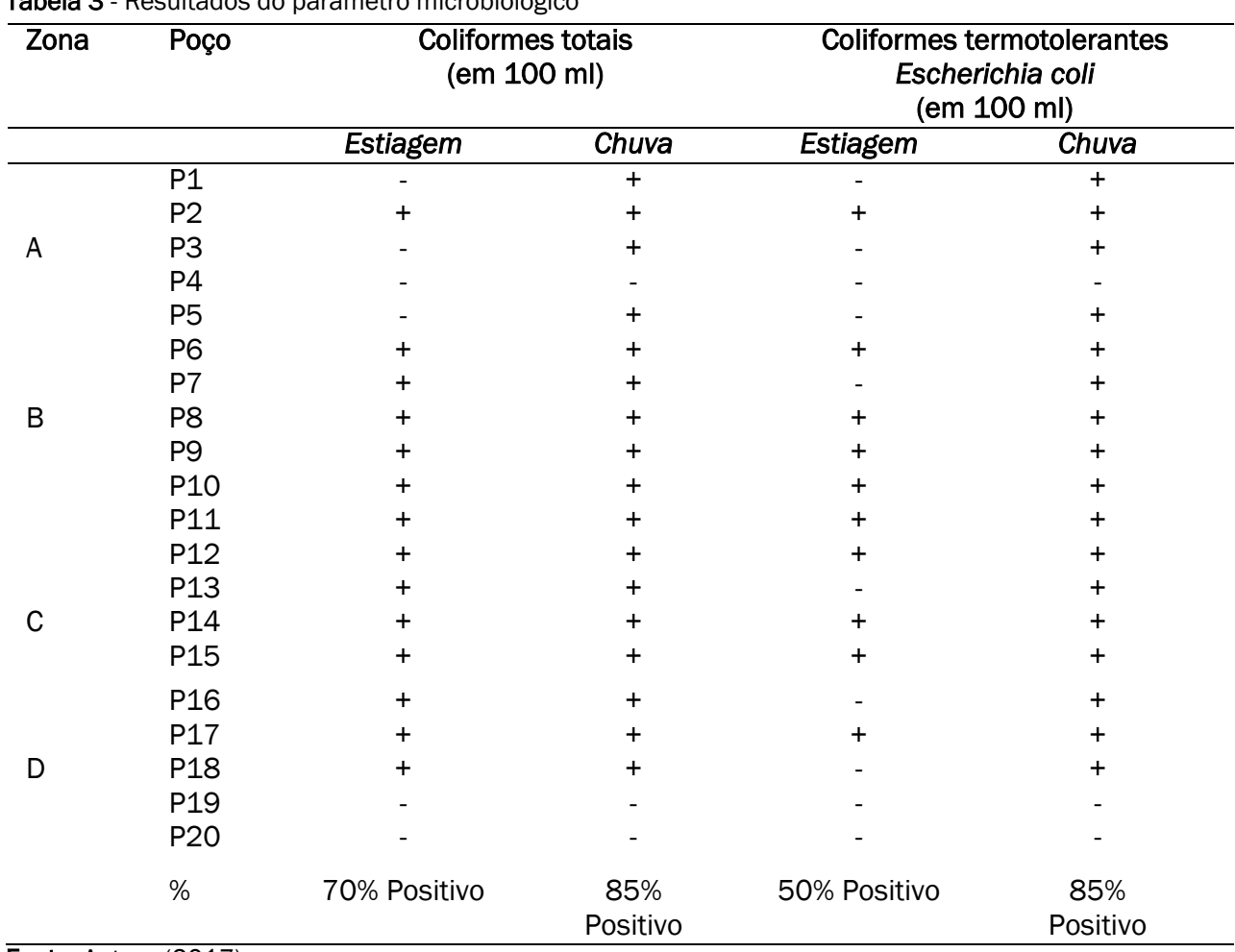

Fonte: Autora (2017)

Nota: $(+)=$ Positivo; $(-)=$ Negativo 
A fonte da contaminação por bactérias pode ser associada ao intenso crescimento populacional que é ocorrente no bairro, provocando o aumento na geração de esgotos, uma vez que, as residências não dispõem de tratamento para seus efluentes domésticos e, na maioria dos casos observados em entrevista, ocorre o emprego extensivo de fossas sépticas próximas aos po- ços (tabela 4). A alarmante presença de Escherichia coli na água durante o período chuvoso, sobrevém devido à carga de poluentes lixiviadas pelas águas das chuvas e altas das marés do Rio Amazonas, elevando o nível das águas subterrâneas e, consequentemente, as concentrações dos poluentes absorvidos pelo solo (REBOUÇAS et al., 2006).

Tabela 4 - Resultados obtidos via questionário

\begin{tabular}{lcccc}
\hline Descrição poço & Média & Desvio Padrão & Mediana & Faixa de Variação \\
\hline Idade & 15,25 & 7,20 & 15 & $4|-| 30$ \\
Profundidade & 12,9 & 3,25 & 13 & $7|-| 20$ \\
Distância Fossa Residência & 18,45 & 7,21 & 22,5 & $8|-| 25$ \\
Distância Fossa Vizinho & 16,11 & 4,39 & 15 & $5|-| 25$ \\
\hline
\end{tabular}

Fonte: Autora (2017)

Nota: Os dados expressos são naturalmente não precisos

Por meio da aplicação do questionário (Tabela 5), tornou-se possível identificar que a maioria das residências do bairro novo horizonte não possui acesso à água fornecida pela CAESA - Companhia de Água e Esgoto do Amapá -, assim como não há tratamento para o esgoto produzido na grande extensão do bairro. Os poços se encontraram em sua maioria com a vedação existente, contudo, alguns revelaram-se com aberturas significativas e tampas com altura próxima ao solo. Sendo, visualmente, o nível topográfico do bairro com consideráveis variações, metade dos poços se encontram em um nível abaixo do córrego, indicando um possível meio de contaminação durante as chuvas (OLIVEIRA et al, 2004; SILVA et al, 2014).

Tabela 5 - Questionário aplicado aos moradores

\begin{tabular}{|c|c|c|c|c|}
\hline \multirow{2}{*}{ Questão } & \multicolumn{2}{|c|}{ SIM } & \multicolumn{2}{|c|}{ NÃO } \\
\hline & $\mathrm{N}^{\circ}$ & $\%$ & $\mathrm{~N}^{\circ}$ & $\%$ \\
\hline A residência possui água fornecida pelo município? & $3 / 20$ & $15 \%$ & $17 / 20$ & $85 \%$ \\
\hline A residência possui tratamento para esgoto sanitário? & $0 / 20$ & $0 \%$ & $20 / 20$ & $100 \%$ \\
\hline A abertura do poço é vedada? & $13 / 20$ & $65 \%$ & $7 / 20$ & $35 \%$ \\
\hline A tampa do poço está acima do solo? & $15 / 20$ & $75 \%$ & $5 / 20$ & $25 \%$ \\
\hline O poço está em um nível mais alto que o córrego? & $10 / 20$ & $50 \%$ & $10 / 20$ & $50 \%$ \\
\hline Você tem conhecimento sobre a distância mínima entre o poço e a fossa? & $6 / 20$ & $30 \%$ & $14 / 20$ & $70 \%$ \\
\hline Quando chove o esgoto transborda e inunda o poço? & $1 / 20$ & $5 \%$ & $19 / 20$ & $95 \%$ \\
\hline É adicionada alguma substância para a purificação da água do poço? & $12 / 20$ & $60 \%$ & $8 / 20$ & $40 \%$ \\
\hline Você realiza algum tratamento antes de beber a água do poço? & $8 / 20$ & $40 \%$ & $12 / 20$ & $60 \%$ \\
\hline
\end{tabular}

Fonte: Autora (2017)

A falta de conhecimento sobre a distância mínima de 15 metros entre o poço e a fossa mostrou-se alarmante. Apenas um poço tem a ocorrência de transbordamento do esgoto no período chuvoso. Quase a metade dos moradores afirmou adicionar alguma substância para purificação da água, porém, contraditoriamente, a maioria não realiza nenhum tratamento da água antes de ingerir. Chegou-se, portanto, a conclusão que todas as substâncias utilizadas pelos moradores para purificação são despejadas diretamente dentro do poço, não surtindo efeito algum, uma vez que a quantidade de substância não equivale ao extenso nível de água no interior do poço (OLIVEIRA et al, 2004; SILVA et al, 2014).

A necessidade de água para beber, aliada ao cenário encontrado reforçou a aplicação da Cartilha Educacional que detalhou a importância e meios de tratamento da água, bem como a importância da proteção e manutenção dos poços. 0 resultado demonstrou-se positivo devido à grande demonstração de interesse sobre $o$ assunto pelos morados, pois muitas informações eram de total desconhecimento, uma vez que a boa qualidade baseavase apenas na estética da água (OLIVEIRA, 2009).
A análise por HCA das amostras de água dos poços em estudo, utilizando os parâmetros cloretos, alcalinidade, dureza, turbidez e sólidos totais, nos revela a semelhança entre os pontos de coleta no período de estiagem e chuva, como demonstrado na figura 4, $\alpha$. Ainda, por meio da análise de PCA (PC1xPC2), é possível observar a similaridade demonstrada em HCA, assim como as tendências à cada parâmetro exposto (figura $4, \beta$ ).

A figura $4, \alpha$ mostra o dendograma relativo à similaridade dos poços segundo as variáveis escolhidas. 0 closter "a” apresenta similaridade entre os poços do período de estiagem, provavelmente pelos valores mais altos do parâmetro de Alcalinidade que variam entre 9,0 - 11,0, e diferença entre os grupos "b" e "c" para o mesmo período. Ainda, observa-se que os poços 01 e 04 estão unidos, possivelmente, por apresentar altos valores de dureza em relação aos demais poços desse grupo.

Para o closter "d" que possui em maioria poços do período de chuva, torna-se provável que a semelhança se dê pelo nível de cloretos que varia entre $8-16$, diferenciando-se pela alcalinidade que sobe consideravelmente. Entre o closter "e" vemos poços de estiagem que apresentam afinidade nos níveis de cloretos, evidenciando a proximidade entre os closter " $d$ " e "e". 
As maiores similaridades são encontradas entre os poços localizados nas zonas $\mathrm{A} \mathrm{e} \mathrm{C}$, um fator esperado devido à proximidade com a área de ressaca que cruza a localização. A alcalinidade e dureza se aproximam na média dos valores no período de estiagem, enquanto que, no período de chuva, a alcalinidade se aproxima de cloretos, provavelmente devido à composição do solo durante a lixiviação pelas águas da chuva.

A figura $\beta$ mostra $p$ gráfico de componente principal 1 versus componente principal 2 . Neste gráfico se distingue facilmente os grupos, podendo observar o peso da CP1 está para o parâmetro da alcalinidade e para CP2 está o parâmetro da dureza, autenticando os resultados expressos pelo dendograma.

A aglomeração central possui padrões similares de resultados e nota-se que o ponto ZCe 15 é um "outlier", podendo se justificar pelo fato de apresentar individualmente uma maior concentração de matéria orgânica na água que influenciou a turbidez durante o período de estiagem e, ainda, por localizar-se próximo a ponto de ressaca (LIMA, 2013).

Figura 4 - Gráficos de análise multivariada dos poços amazonas nos períodos de estiagem e chuva no bairro Novo Horizonte da cidade de Macapá, usando os descritores alcalinidade $(A)$, cloretos $(C)$, dureza (D), sólidos totais e turbidez (T) das respectivas águas. Dendograma com closters identificados de a - i $(\alpha)$; Gráficos de PCA dos scores com closters identificados por círculos ( $\beta$ ); tabulação dos dados brutos ( $($ )

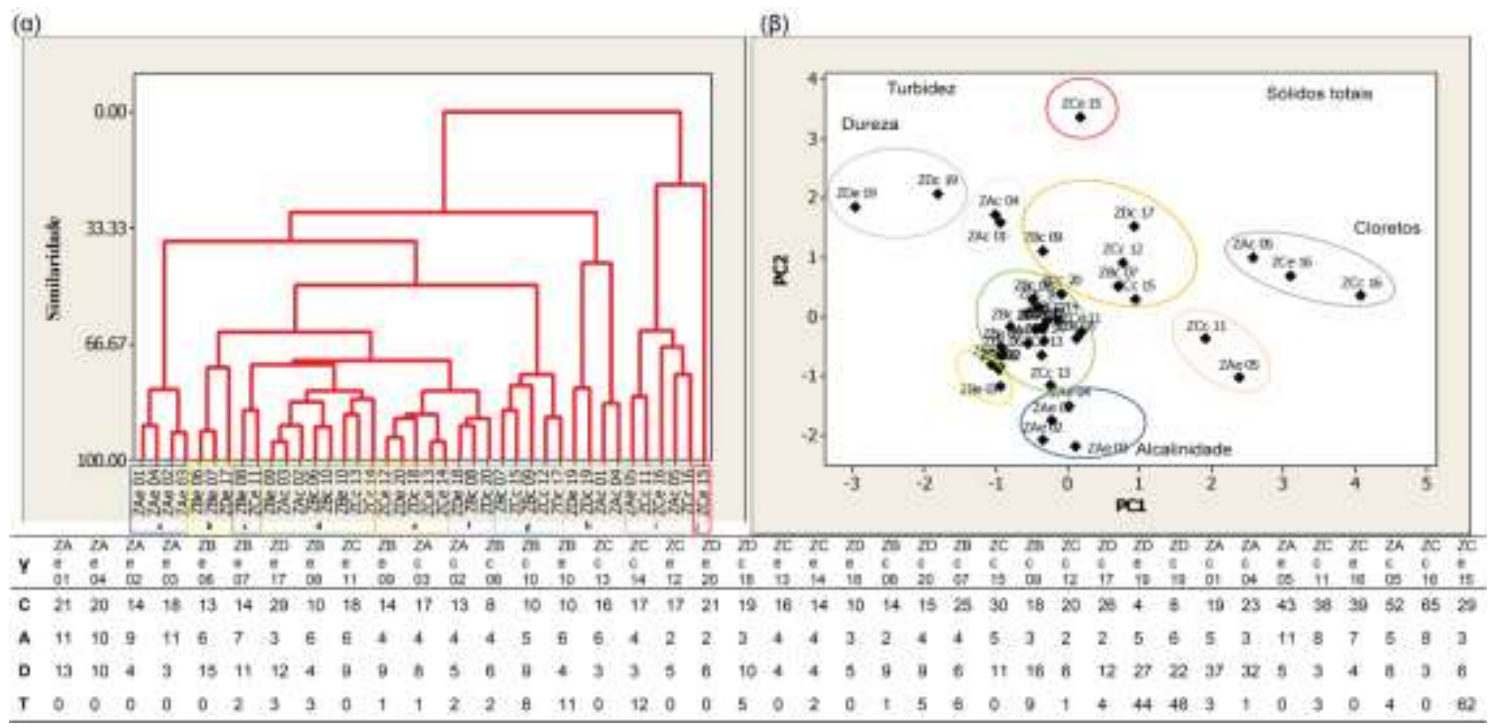

\section{CONCLUSÕES}

A técnica estatística multivariada por meio da aplicação da HCA e PCA promoveu a melhor identificação dos grupos das variáveis de qualidade de água do bairro Novo Horizonte, uma vez que, a maior tendência de variações ocorreu entre as zonas A e C. Ainda, permitiu a definição de três variáveis que nortearam a formação dos grupos e a interpretação, sendo: alcalinidade (presença do gás carbônico e sais dissolvidos em maior quantidade), dureza e cloretos (alcance de fontes de poluição prolixa, como esgoto doméstico).

O bairro novo horizonte apresentou uma baixa qualidade da água subterrânea, mediante a presença de coliformes e variação significativas de $\mathrm{pH}$. Através do questionário é possível observar que os residentes fazem uso de água mineral para beber, contudo, devido ao baixo recurso financeiro não há como manter este consumo cotidiano, determinando a necessidade de ingerir a água do poço, cuja qualidade mostrou-se inadequada.

O interesse despertado por parte dos residentes tornou-se um resultado positivo para essa pesquisa em meio à preocupante situação local. Consideramos que a gestão pública do estado do Amapá deve tomar as providências necessárias para o abastecimento regular e completo do bairro novo horizonte, assim como procurar desenvolver uma veiculação de informações sobre as medidas de segurança para abertura de poços e construção de fossas sépticas, a fim de evitar que se tornem fontes de contaminação para o aquífero, suscitando a diminuição dos índices de doenças transmitidas pela água e ampliação da qualidade de vida.

\section{REFERÊNCIAS}

ABAS. Associação Brasileira de Águas Subterrâneas. Disponível em: <http://www.abas.org/educacao_pocos.php>. Acesso em: 04 de abril de 2016.

AMERICAN PUBLIC HEALTH ASSOCIATION. Water Environment Federation. Standard methods for the examination of water and wastewater, v. 19, 1995.

ANA. Agência Nacional de Águas. Atlas Brasil: Abastecimento Urbano de Água: Panorama Nacional. Brasília, DF, 2010. Vol. 1.

BACCl et al. Educação para Água. Dossiê água. Estudos Avançados. v. 22, n. 63, São Paulo, p. 211-226, 2008.

BRASIL. Ministério da Saúde. Fundação Nacional de Saúde. Manual de controle da qualidade da água para técnicos que trabalham em ETAS /Ministério da Saúde, Fundação Nacional de Saúde. - Brasília: FUNASA, 2014.

. Ministério da Saúde. Portaria $n{ }^{\circ} 2.914$, de 12 de Dezembro de 2011. Dispõe sobre normas de potabilidade de água para o consumo humano. Brasília: SVS, 2011. Oficial da União, 14 de dezembro de 2011.

- Ministério da Saúde. Secretaria de Vigilância em Saúde. Vigilância e controle da qualidade da água para consumo humano/Ministério da Saúde, Secretaria de Vigilância em Saúde. - Brasília: Ministério da Saúde, 2006. 212 p. - (Série B. Textos Básicos de Saúde) 
BUCKALEW, D. W. et al. A long-term study comparing membrane filtration with Colilert ${ }^{\circledR}$ defined substrates in detecting fecal coliforms and Escherichia coli in natural waters. Journal of environmental management, v. 80, n. 3, p. 191-197, 2006.

CHOWDHURY, Tarit Roy et al. Arsenic poisoning in the Ganges delta. Nature, v. 401, n. 6753, p. 545-546, 1999.

Dicionário Enciclopédico Livre De Geociências. Hidrogeologia. Disponível em: <http://www.dicionario.pro.br/index.php/Hidrogeologia>. Acesso em: 01 de novembro de 2016.

IBGE. Instituto Brasileiro de Geografía e Estadística. IBGE Cidades Censo 2010. Disponível em: <http://cidades.ibge.gov.br>. Acesso em: 18 de abril de 2016.

GROTT, S. L. Água subterrânea para consumo humano em Macapá: subsídios às políticas públicas de saneamento e recursos hídricos. Dissertação (mestrado) - Fundação Universidade Federal do Amapá, Programa de Pós-graduação em Direito Ambiental e Políticas Públicas. Macapá, 2016. $119 \mathrm{f}$

LIMA, D. C. I. Caracterização do abastecimento público de água potável no município de Macapá. Trabalho de Conclusão de Curso (graduação) Fundação Universidade Federal do Amapá, Coordenação do Curso de Bacharelado em Ciências Ambientais. Macapá, 2013. 45 f.

MINGOTI, S. A. Análise de dados através de estatística multivariada: uma abordagem aplicada. Belo Horizonte: Editora UFMG, 2005.

NERY et al. Estudo físico-químico preliminar de águas subterrâneas na área do bairro zerão, Macapá (AP). CONGRESSO BRASILEIRO DE ÁGUAS SUBTERRÂNEAS, 17.,2012. Anais...

OLIVEIRA, R. I. R. e. GASTAL, M. L. A. Educação formal fora da sala de aula - olhares sobre o ensino de ciências utilizando espaços não formais. VII ENCONTRO NACIONAL DE PESQUISA EM EDUCAÇÃO EM CIÊNCIAS,6. 2009. Anais.. Florianópolis, 8 de novembro de 2009.
OLIVEIRA et al. Vulnerabilidade Natural E Sazonalidade Do Aquífero Livre No Loteamento Marabaixo III - Macapá - AP. CONGRESSO BRASILEIRO DE ÁGUAS SUBTERRÂNEAS, 13., 2004. Anais...

PARSONS, Timothy R. A Manual of chemical \& biological methods for seawater analysis. elsevier, 2013.

REBOUÇAS, A. Dossiê desenvolvimento rural. Estudos Avançados, v.15, n. 4, São Paulo Sept./Dec. 2001

REBOUÇAS, A. Uso inteligente da água. São Paulo: Escrituras Editora, 2004.

REBOUÇAS, A. C.; BRAGA, B.; TUNDISI, J. G. Águas doces no Brasil: capital ecológico, uso e conservação. 3. ed. São Paulo: Escrituras, 2006.

R Core Team. R. A language and environment for statistical computing. R Foundation for Statistical Computing, Vienne, Austrália. Disponível em: http://www.R-project.org/.

SILVA, E. S. e. OLIVEIRA, J. C.S. Avaliação da qualidade da água da Reserva Particular do Patrimônio Natural (RPPN) Seringal Triunfo, Rio Araguari, Ferreira Gomes - Ap- Brasil. Biota Amazônia, v. 4, n. 2, p. 28-42, 2014.

SILVA et al. Parâmetros físico-químicos da água utilizada para consumo em poços artesianos na cidade de Remigio-Pb. Revista Águas Subterrâneas, v. 31, n. 2, 2017.

SILVA et al. Impacto Físico-Químico da Deposição de Esgotos em Fossas Sobre As Águas de Aquífero Freático Em Jiparaná - Ro. REA - Revista de estudos ambientais (Online) v.11, n. 2, p. 101-112, jul./dez. 2009.

VASCONCELOS, M. B. O que são poços? Um panorama das terminologias utilizadas para captações de águas subterrâneas. Revista Águas Subterrâneas, v. 31, n. 2, 2017.

VILLAR, P. C. As águas subterrâneas e o direito à água em um contexto de crise. Ambiente \& Sociedade. São Paulo v. 19, n. 1, p. 83-102, jan./mar. 2016 